\title{
Thoracoscopic ethanol injection and radiofrequency ablation for the treatment of hepatocellular carcinoma located immediately under the diaphragm
}

\author{
KAZUTAKA KUROKOHCHI ${ }^{1,2}$, SHUNICHI HIRAI ${ }^{3}$, TOMOHIRO OHGI ${ }^{1,2}$, MASAHIRO ONO $^{1,2}$, \\ AKIRA YOSHITAKE ${ }^{1,2}$, KAZUO EBARA $^{3}$, YASUHIRO KITAMURA ${ }^{3}$, YOSHITAKA KASAI ${ }^{3}$, \\ TSUYOSHI MAETA ${ }^{2}$, TAKAAKI KIUCHI ${ }^{4}$, TSUTOMU MASAKI ${ }^{1}$, HIROHITO YONEYAMA $^{1}$, \\ FUMIKAZU KOHI $^{2}$ and SHIGEKI KURIYAMA ${ }^{1}$ \\ ${ }^{1}$ Third Department of Internal Medicine, Kagawa University School of Medicine, 1750-1 Ikenobe, Miki-cho, \\ Kita-gun, Kagawa 761-0793; Departments of ${ }^{2}$ Gastroenterology, ${ }^{3}$ Surgery and ${ }^{4}$ Radiology, \\ KKR Takamatsu Hospital, 4-18 Tenjinmae, Takamatsu, Kagawa 760-0018, Japan
}

Received March 7, 2006; Accepted April 27, 2006

\begin{abstract}
We previously reported that the combination therapy of percutaneous ethanol injection and radiofrequency ablation (PEI-RFA) was more effective than RFA alone in inducing wider coagulated necrosis for the treatment of hepatocellular carcinoma (HCC). In the present study, we thoracoscopically applied the combination therapy to the treatment of HCC located immediately under the diaphragm. RFA electrode and ethanol injection needle were inserted into the tumor through the right side of the diaphragm in 6 patients with HCC close to the diaphragm. In all cases, the tumor was completely ablated with enough safety margin around the tumor. No local tumor recurrence has been observed in a relatively short-time followup period. The volume of coagulated necrosis and the energy requirement for coagulation in thoracoscopic ethanol injection and RFA (T-EI-RFA) were comparable to those of PEI-RFA. Although HCC located immediately under the diaphragm is difficult to treat with a percutaneous approach due to the poor visualization by ultrasonography, T-EI-RFA is considered to be an effective treatment modality.
\end{abstract}

\section{Introduction}

Hepatocellular carcinoma (HCC) is one of the most serious malignancies worldwide, especially in Asian countries due to the high frequency of exposure to hepatitis virus. Despite the

Correspondence to: Dr Shigeki Kuriyama, Third Department of Internal Medicine, Kagawa University School of Medicine, 1750-1 Ikenobe, Miki-cho, Kita-gun, Kagawa 761-0793, Japan

E-mail: skuriyam@med.kagawa-u.ac.jp

Key words: radiofrequency ablation, ethanol injection, hepatocellular carcinoma, thoracoscopy intensive efforts for the development of treatment modalities for HCC, the prognosis of HCC remains relatively poor $(1,2)$. The feasibility of gene therapy for HCC has, therefore, been investigated intensively in animal models using viral and non-viral systems (3-13), since these are important for evaluating new treatment modalities for HCC.

Tumor ablation technologies such as microwave, laser, radiofrequency ablation (RFA) and cryoablation have been shown to be reliable and effective for the treatment of HCC (14-17) and metastatic liver cancer $(18,19)$. Among these treatment modalities, RFA now plays a central role in the local treatment of HCC, because RFA can induce wider coagulated necrosis in fewer sessions without major complications. However, several limitations of RFA have been pointed out, such as limited coagulated necrosis and relatively frequent local tumor recurrences. To overcome these weaknesses, we have developed a novel combination therapy of percutaneous ethanol injection (PEI) and RFA and showed that combined use of PEI prior to RFA was able to enhance the therapeutic effect with smaller energy requirement compared with RFA alone (20-24). Although PEI-RFA was shown to enlarge the area of coagulated necrosis, there are cases with HCC that are difficult to treat with a percutaneous approach due to the location of HCC. For example, HCC protruding from the liver surface is difficult to treat with percutaneous RFA due to the risk of bleeding from the tumor. Furthermore, HCC located immediately under the diaphragm is difficult to treat with percutaneous RFA due to the poor visualization by ultrasonography (US). Therefore, other approaches of RFA are desirable for the treatment of these tumors. We have already shown that laparoscopic ethanol injection and RFA was safe and effective for the treatment of HCC protruding from the liver surface. In the present study, we applied the combination therapy of ethanol injection and RFA to the throacoscopic treatment (T-EI-RFA) of HCCs located immediately under the diaphragm and evaluated its effectiveness from the standpoint of the width of induced coagulated necrosis and energy requirement for ablation. 


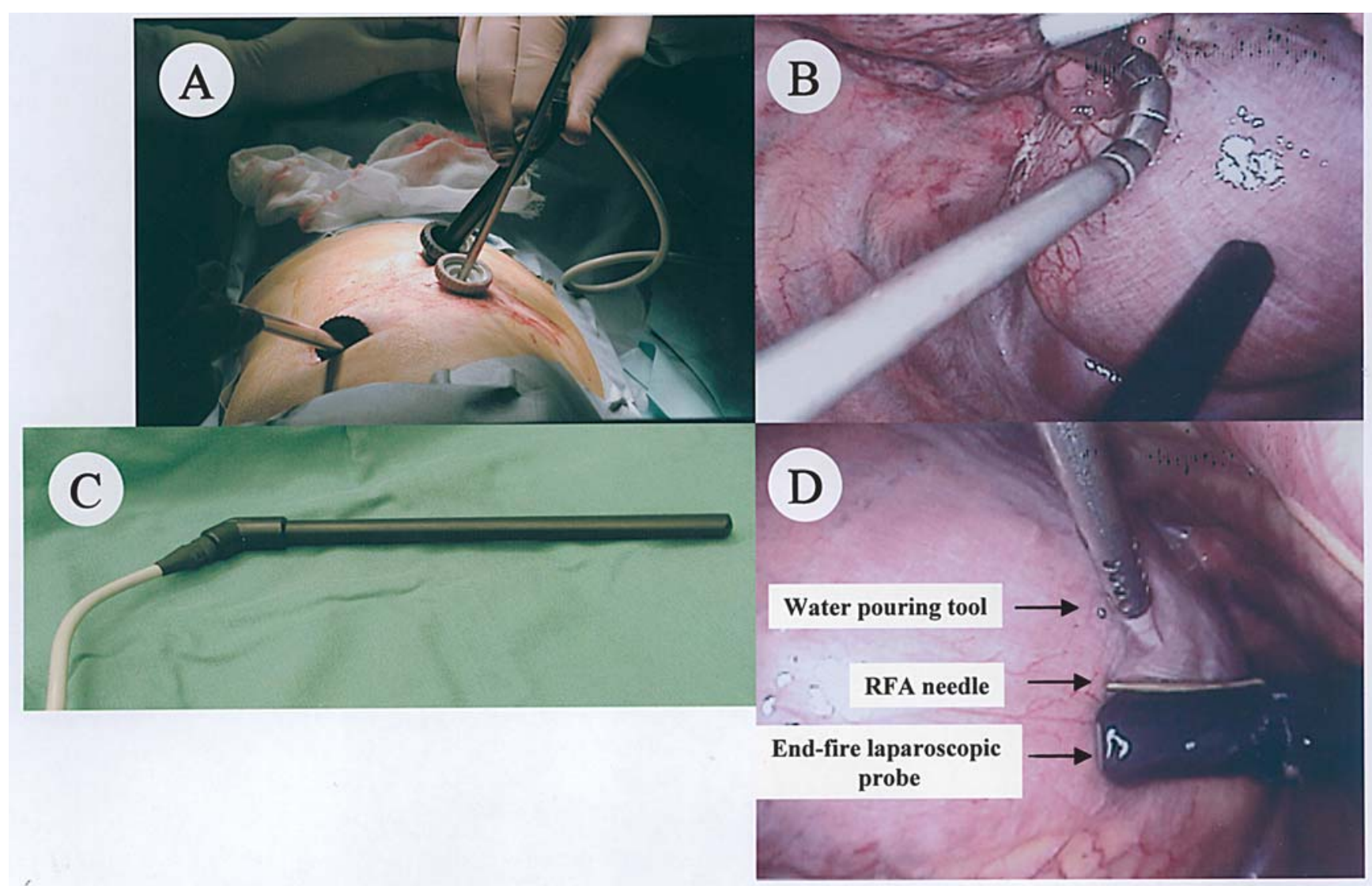

Figure 1. Appearance of T-EI-RFA are shown. Three ports for the thoracoscope, End-fire laparoscopic probe (ALOKA UST-52109) (C) and water-pouring tool were inserted into the pleural cavity through intercostals space (A). After putting the collapsed right lung aside by a snake-retractor, the right-side diaphragm was exposed (B). End-fire laparoscopic probe (C) was leaded to the surface of the exposed diaphragm and the tumor immediately under the diaphragm was identified. After visualizing the tumor by US, RFA electrode was inserted into the tumor through the channel along the End-fire laparoscopic probe (D). During the ablation, cooling water was intermittently poured on the surface of the diaphragm to prevent a thermal burn of the diaphragm (D).

\section{Patients and methods}

Patients. T-EI-RFA was performed to 6 patients $(3$ male and 3 females; mean age of 58 years) with HCC (1-2.5 $\mathrm{cm}$ in diameter) located immediately under the diaphragm. One HCC was located in the segment 6 (S6) of the liver and others were in S8. All of these studies were conducted under the informed consent at the time of enrollment.

Equipments and RFA procedures. Patients were put under general anesthesia and one-lung (left lung) ventilation, and in a left-decubitus position. Three ports for the thoracoscope, End-fire laparoscopic probe (ALOKA UST-52109) and waterpouring tool were inserted into the pleural cavity through intercostal space (Fig. 1A). After putting the collapsed right lung aside by a snake-retractor, the right-side diaphragm was exposed (Fig. 1B). End-fire laparoscopic probe was leaded to the surface of the exposed diaphragm and the tumor immediately under the diaphragm was identified by US (ALOKA ProSound SSD-3500) (Fig. 1C). After visualizing the tumor by US, an RFA electrode was inserted into the tumor through the channel along the End-fire laparoscopic probe (Fig. 1D), and then a 21-gauge PEI needle was inserted into the tumor through the same channel. RTC system equipped with RF3000 Generatior and LeVeen needle electrode (Boston Scientific), Cool-tip RF System (Radionics,
Burlington, USA) and RITA system equipped with Model 1500X RF generator were used for RFA. In all cases, pure ethanol $(99.8 \%)$ was slowly injected into the tumor prior to the initiation of RFA. Since we recently learned that time-lag performance of RFA after ethanol injection was more effective in inducing wider coagulated necrosis compared with routine RFA and no time-lag performance of RFA after ethanol injection (25), RFA was started 5 min after ethanol injection. The volume of injected ethanol was always kept below the double volume of the estimated tumor volume. When the Coo-tip RF system was used for RFA, the ablation was started from $30 \mathrm{~W}$ of power output and stepwise increased by $20 \mathrm{~W}$ every 2-3 min. After the end of ablation at $50 \mathrm{~W}$ of power output, circulating cooling water was stopped once and the temperature of the RFA electrode was checked. The ablation was terminated when the temperature of the RFA electrode indicated over $70^{\circ} \mathrm{C}$. When the RTC system was used, the roll-off was achieved once with the electrode being half-opened, and then twice with the electrode being fully-opened. In the case of the RITA system, the umbrella-shaped electrode was stepwise opened and the power output was stepwise increased from $20 \mathrm{~W}$. The fullyopened electrode was kept for $10 \mathrm{~min}$ after the temperature of the electrode had reached $80^{\circ} \mathrm{C}$. During the ablation, cooling water was poured to the surface of the diaphragm to prevent a thermal burn of the diaphragm (Fig. 1D). 


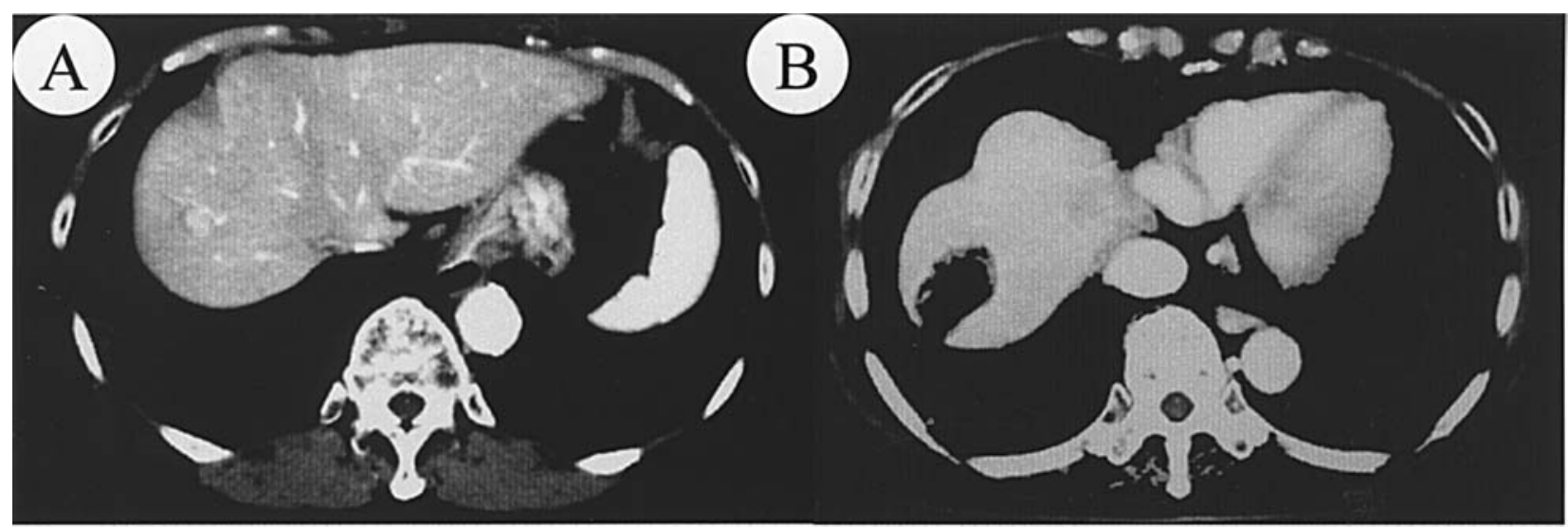

Figure 2. A case of HCC located immediately under the diaphragm (S8 of the liver) treated successfully with T-EI-RFA. Helical dynamic CT images before (A) and after (B) T-EI-RFA. Five minutes after the injection of $3 \mathrm{ml}$ of ethanol into the tumor, RFA was performed by Cool-tip RF System at $30 \mathrm{~W}$ for $2 \mathrm{~min}, 50 \mathrm{~W}$ for $3 \mathrm{~min}$ and $80 \mathrm{~W}$ for $3 \mathrm{~min}, 8 \mathrm{~min}$ in total. Enough ablated area including safety margin was obtained after the treatment.

Evaluation of therapeutic efficacy. Five to seven days after T-EI-RFA, contrast-enhanced helical dynamic computed tomography (CT) was performed to evaluate the response to T-EI-RFA. Tumor necrosis was considered to be complete when no foci of early enhancement were seen around the original region.

Evaluation of energy requirement for ablation. Energy requirement for ablation was calculated as follows: energy $(\mathrm{J})=$ watt $(\mathrm{W}) \times$ duration of ablation (sec). The length of coagulated necrosis was measured from the late phase of helical dynamic CT. The approximation volume of whole coagulated necrosis area $\left(\mathrm{V} 1 \mathrm{~cm}^{3}\right)=4 / 3 \pi \times \mathrm{r} 1(\mathrm{~cm}) \times \mathrm{r} 2(\mathrm{~cm})$ x r3 $(\mathrm{cm})(\mathrm{r} 1$, longest diameter/2; r2, shortest diameter/2; r3, height/2); volume of tumorous lesion before ablation $\left(\mathrm{V} 2 \mathrm{~cm}^{3}\right)$ $=4 / 3 \pi$ x r4 $(\mathrm{cm}) \times \mathrm{r} 5(\mathrm{~cm}) \times \mathrm{r} 6(\mathrm{~cm}) / 2,(\mathrm{r} 4$, longest diameter $/ 2$; r5, shortest diameter/2; r6, height/2). The volume of marginal coagulated necrosis was calculated by subtracting V2 from V1. Energy requirements for the whole and marginal coagulated necrosis per unit volume $\left(\mathrm{J} / \mathrm{cm}^{3}\right)=$ energy/volume of whole coagulated necrosis and energy/volume of marginal coagulated necrosis, respectively.

Statistical analysis. Statistical analysis was performed using Macintosh software StatView II (Version 5.0). Statistical significance between the groups of Time-lag T-EI-RFA and PEI-RFA was analyzed by non-parametric analysis (Mann Whitney $U$ test) and significant difference was accepted at $\mathrm{p}<0.05$.

\section{Results}

Representative cases of HCC treated with T-EI-RFA. We innovated the novel combination therapy, PEI-RFA, and have previously applied it percutaneously or laparoscopically. In this study, we applied the combination therapy thoraco-scopically for the treatment of HCC located immediately under the right diaphragm. We treated 6 patients with HCC located in the S8 or S6 segment of the liver with T-EI-RFA. One case with HCC located in S8 of the liver treated successfully with T-EI-RFA is shown in Figs. 2-4. An

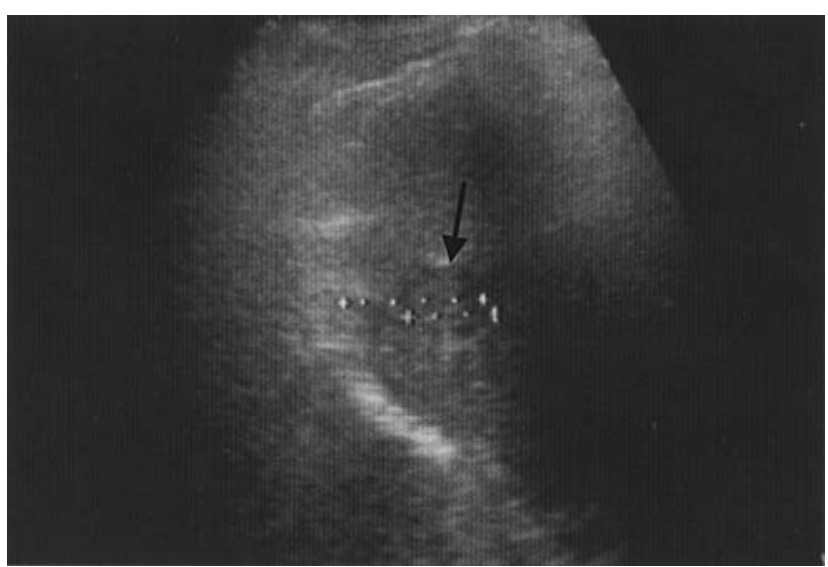

Figure 3. US image of the tumor $(1.5 \mathrm{~cm}$ in diameter) from right intercostal space. The tumor with halo was visualized immediately under the right side of the diaphragm. The tumor was easily hidden by the lung moving up and down with respiration

HCC tumor (1.5 cm in diameter) was located in S8 of the liver immediately under the right diaphragm. The tumor was enhanced in the early vascular phase of helical dynamic CT (Fig. 2A). HCC located immediately under the diaphragm is difficult to treat with percutaneous local treatment due to the poor visualization of the entire tumor by US. Indeed, the tumor was easily hidden by the right lung moving up and down with respiration, and was difficult to visualize by US (Fig. 3). Therefore, we chose a thoracoscopic approach for the treatment. The patient was laid down at a left-decubitus position under one-lung ventilation. Three ports were inserted into the pleural cavity through intercostal space (Fig. 1A). The tumor located immediately under the right diaphragm was searched by the End-fire laparoscopic probe through the diaphragm and the tumor with halo was clearly visualized by US (Fig. 4A). After inserting the Cool-tip RF electrode through the channel of the End-fire laparoscopic probe into the tumor, PEI needle was also inserted along the electrode, and then $3 \mathrm{ml}$ of pure ethanol (99.8\%) was injected into the tumor as the entire region of the tumor was filled with ethanol (Fig. 4B). Five minutes after the injection of 3 


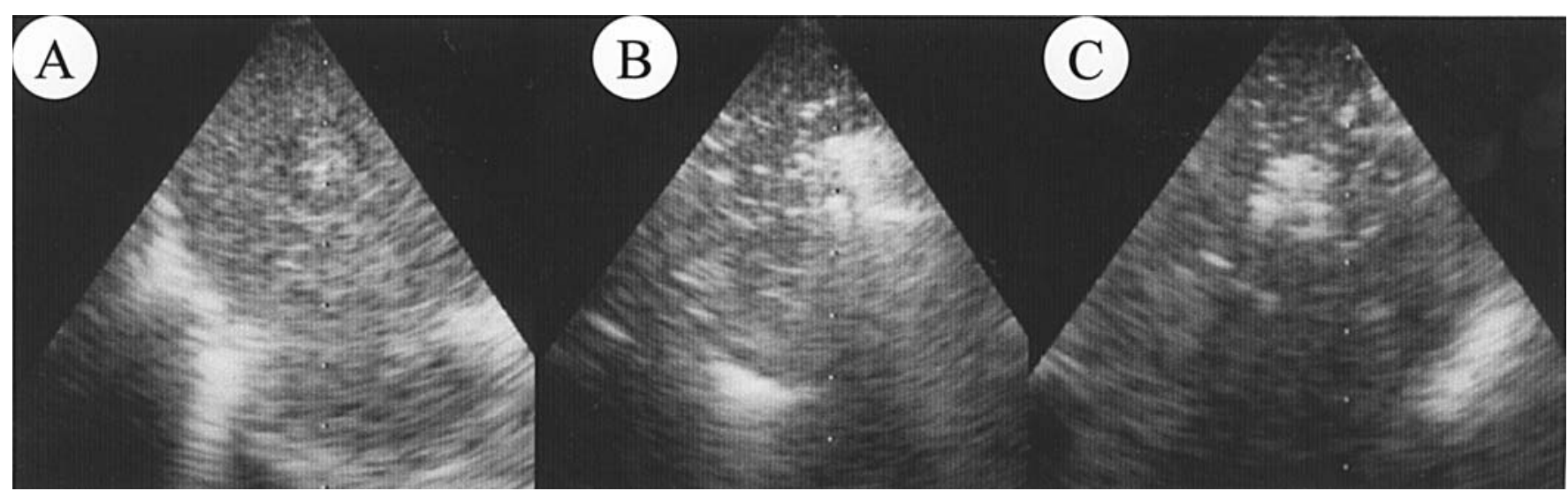

Figure 4. US images of the tumor from the surface of the diaphragm. The round-shaped high echo with halo was clearly visualized immediately under the diaphragm (A). The entire region of the tumor changed to white after the injection of ethanol (B) and after the ablation (C).

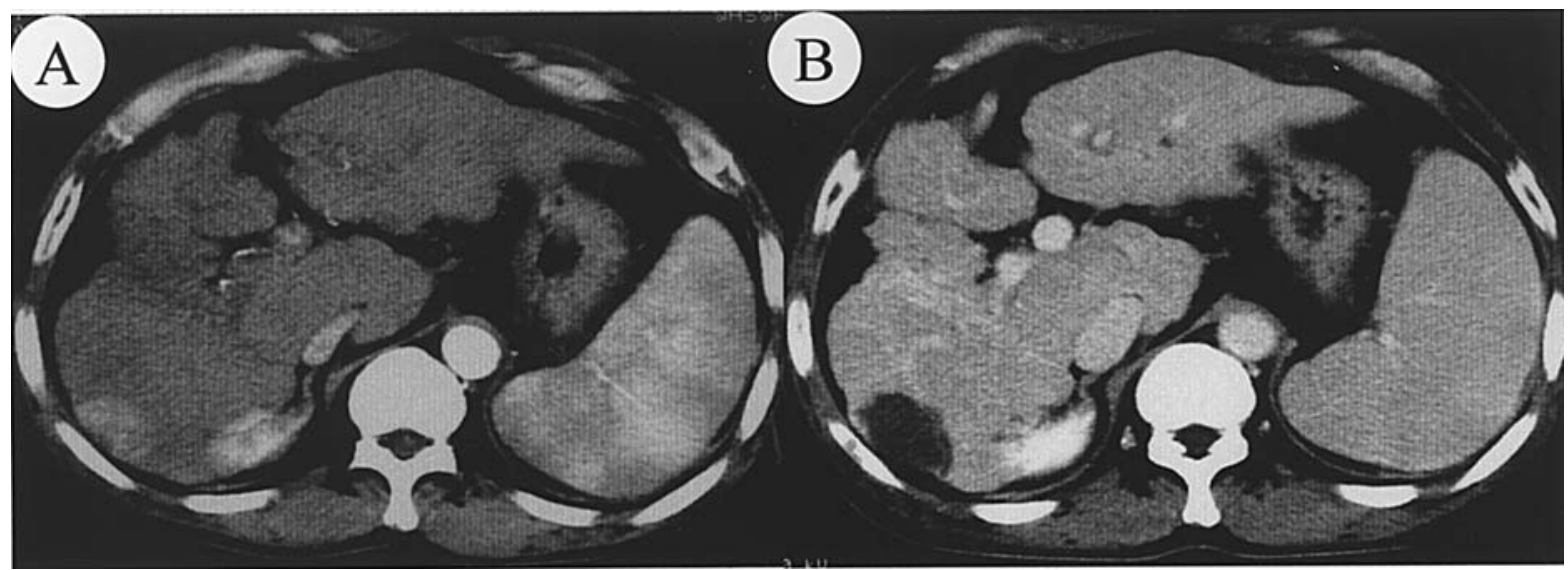

Figure 5. A case of HCC located immediately under the diaphragm ( $\mathrm{S} 6$ of the liver) treated successfully with T-EI-RFA. Helical dynamic CT images before (A) and after (B) T-EI-RFA. Five minutes after the injection of $7 \mathrm{ml}$ of ethanol into the tumor, RFA was performed by Cool-tip RF System at $30 \mathrm{~W}$ for $2 \mathrm{~min}$, $50 \mathrm{~W}$ for $2 \mathrm{~min}$ and $70 \mathrm{~W}$ for $3 \mathrm{~min}, 7 \mathrm{~min}$ in total. Enough ablated area including safety margin was obtained after the treatment.

$\mathrm{ml}$ of ethanol, RFA was performed at $30 \mathrm{~W}$ for $2 \mathrm{~min}, 50 \mathrm{~W}$ for $3 \mathrm{~min}$ and $80 \mathrm{~W}$ for $3 \mathrm{~min}, 8 \mathrm{~min}$ in total. The final temperature was $75^{\circ} \mathrm{C}$. As the ablation proceeded, the entire tumor was covered with high echo and the tumor was visualized as a round white echo after ablation (Fig. 4C). Helical dynamic CT taken 5 days after ablation revealed the ablated area covering the entire tumor with a safety margin (Fig. 2B).

Another case with HCC treated successfully with T-EI-RFA is shown in Fig. 5. An HCC tumor (2.5 cm in diameter) was located in the edge of S6 of the liver. Although the tumor was located in the lower-posterior region of the liver, the tumor was clearly visualized through the diaphragm by the End-fire laparoscopic echo probe. After the injection of $7 \mathrm{ml}$ of ethanol, RFA was performed at $30 \mathrm{~W}$ for $2 \mathrm{~min}, 50 \mathrm{~W}$ for $2 \mathrm{~min}$ and $70 \mathrm{~W}$ for $3 \mathrm{~min}, 7 \mathrm{~min}$ in total. The final temperature was $75^{\circ} \mathrm{C}$. Helical dynamic CT taken 5 days after ablation revealed the ablated area covering the whole tumor with a sufficient safety margin (Fig. 5B).

Comparison of the volume of coagulated area, total energy requirement and energy requirement for the whole and marginal coagulated necrosis per unit of volume between T-EI-RFA and PEI-RFA groups. In 6 cases treated with T-EIRFA, the volume of the whole and marginal coagulated necrosis, mean total energy requirement and energy requirement for inducing whole and marginal coagulated necrosis per unit volume were calculated. The data were compared with those of percutaneous treatment (Time-lag PEI-RFA) of our previous study (25). The volume of coagulated necrosis area, total energy requirement and energy requirement for inducing the whole and marginal coagulated necrosis per unit volume in the time-lag T-EIRFA and PEI-RFA groups are shown in Table I. Although the mean total energy requirement of the T-EI-RFA group was larger than that of PEI-RFA group, none of the data showed any significant difference between the groups. These data suggested that the combination therapy of ethanol injection and RFA could induce comparable coagulated necrosis of HCC irrespective of the approaches (percutaneous and thoracoscopic) to the tumors.

Therapeutic efficacy of T-EI-RFA. Among 6 patients with HCC treated with T-EI-RFA, no local tumor recurrence has 
Table I. Comparison of the volume of coagulated necrosis, total energy requirement and energy requirement per unit volume for inducing coagulation in T-EI-RFA and PEI-RFA.

\begin{tabular}{|c|c|c|c|c|c|c|c|c|c|c|c|}
\hline & $\begin{array}{l}\mathrm{T}-\mathrm{S} \\
(\mathrm{cm})\end{array}$ & $\begin{array}{c}\mathrm{EtOH} \\
(\mathrm{ml})\end{array}$ & $\begin{array}{c}\mathrm{L} \\
(\mathrm{cm})\end{array}$ & $\begin{array}{c}\mathrm{S} \\
(\mathrm{cm})\end{array}$ & $\begin{array}{c}\mathrm{H} \\
(\mathrm{cm})\end{array}$ & $\begin{array}{c}\mathrm{V} \\
\left(\mathrm{cm}^{3}\right)\end{array}$ & $\begin{array}{c}\mathrm{M} \\
\left(\mathrm{cm}^{3}\right)\end{array}$ & $\begin{array}{c}\text { T-ENE } \\
(\mathrm{J})\end{array}$ & $\begin{array}{c}\text { T-ENE/V } \\
\left(\mathrm{J} / \mathrm{cm}^{3}\right)\end{array}$ & $\begin{array}{c}\text { T-ENE/M } \\
\left(\mathrm{J} / \mathrm{cm}^{3}\right)\end{array}$ & $\begin{array}{c}\text { P-No recur } \\
\text { (months) }\end{array}$ \\
\hline Time-lag & & & & & & & & & & & \\
\hline $\begin{array}{l}\text { T-EI-RFA } \\
(\mathrm{n}=6)\end{array}$ & $22 \pm 0.2$ & $4.0 \pm 0.7$ & $3.5 \pm 0.6$ & $3.5 \pm 0.5$ & $3.2 \pm 0.2$ & $20.8 \pm 2.8$ & $14.6 \pm 2.2$ & $34621 \pm 6710$ & $1696 \pm 185$ & $1882 \pm 326$ & $6.6 \pm 0.7$ \\
\hline Time-lag & & & & & & & & & & & \\
\hline $\begin{array}{l}\text { PEI-RFA } \\
(\mathrm{n}=33)\end{array}$ & $1.9 \pm 0.2$ & $3.0 \pm 1.8$ & $3.5 \pm 0.6$ & $2.9 \pm 0.5$ & $3.1 \pm 0.6$ & $17.1 \pm 7.1$ & $15.3 \pm 7.2$ & $24144 \pm 9534$ & $1569 \pm 792$ & $1842 \pm 1048$ & - \\
\hline
\end{tabular}

Six HCCs were treated with time-lag T-EI-RFA, while 33 HCCs were treated with time-lag PEI-RFA. After treatment, the longest and the shortest diameters, and the height of the coagulated necrosis were estimated by helical dynamic CT and the approximate volume of coagulated necrosis was calculated. Abbreviations: T-S, tumor size; EtOH, amount of injected ethanol; L, longest diameter; S, shortest diameter; $\mathrm{H}$, height; $\mathrm{V}$, volume of coagulated necrosis; $\mathrm{M}$, volume of marginal coagulation; T-ENE, total energy requirement; T-ENE/V, per unit volume of energy requirement for whole coagulation; T-ENE/M, per unit volume of energy requirement for inducing marginal coagulation; P-No recur, mean period (months) of no local recurrence of the tumor. The data of time-lag PEI-RFA is quoted from our previous study (25). No data showed any significant difference between the groups of T-EI-RFA and PEI-RFA.

been observed in a relatively short follow-up period. The mean follow-up period after T-EI-RFA is 6.6 months.

\section{Discussion}

RFA technique has become the mainstream of non-surgical treatment modalities for HCC in clinical settings (16). In contrast to its efficacy, it is pointed out that the area of coagulated necrosis induced by RFA is still limited. Therefore, tumors within $3 \mathrm{~cm}$ in diameter are thought to be good candidates for RFA therapy. To enhance the therapeutic effect of RFA, several treatment modalities have been applied additionally to local treatment. Combined use of transcatheter arterial chemoembolization or saline injection therapy with RFA has been reported to enlarge the extent of induced coagulation (27-33). As one of the optional combination therapies, we have shown that injection of ethanol prior to RFA (PEI-RFA) markedly enlarged the induced coagulated necrosis in human $(20,21)$ and in bovine livers (33). Furthermore, we showed that PEI-RFA is a less invasive treatment modality from the standpoint of energy requirement for inducing coagulated necrosis (24). In the present study, we thoracoscopically applied this combination therapy for the treatment of HCC located immediately under the diaphragm. Although every $\mathrm{HCC}$ in the liver may be treatable by percutaneous RFA, it is true that some HCCs are difficult to treat with percutaneous RFA. For example, HCC at the surface of S3 is sometimes difficult to treat due to the close location of the heart. HCC located immediately under the diaphragm are also difficult to treat due to the close location of the lung. For the treatment of HCC close to the diaphragm, percutaneous approaches are attempted by making space by artificial pleural effusion. In this treatment, a large amount, approximately 1 liter, of $5 \%$ of glucose or saline, were infused into the pleural cavity under local anesthesia and patients sometimes feel discomfort or pain. Furthermore, there are some tumors that are difficult to visualize clearly by US even under artificial pleural effusion. In contrast, patients treated with T-EI-RFA do not feel any discomfort because of general anesthesia, and the tumor can be clearly visualized by US because the distance between the echo probe and the tumor is shorter in T-EI-RFA compared with a percutaneous approach under artificial pleural effusion. Thus, T-EI-RFA may be an option for the treatment of HCC located immediately under the diaphragm.

In conclusion, T-EI-RFA is relatively easy to perform and may be an effective option for the treatment of HCC. T-EIRFA may open up a new avenue for the treatment of HCC.

\section{References}

1. Venook AP: Treatment of hepatocellular carcinoma: too many options? J Clin Oncol 12: 1323-1334, 1994.

2. Colleoni M, Gaion F, Liessi G, Mastropasqua G, Nelli P and Manente P: Medical treatment of hepatocellular carcinoma: any progress? Tumori 80: 315-326, 1994.

3. Kuriyama S, Yoshikawa M, Ishizaka S, Tsujii T, Ikenaka K, Kagawa T, Morita N and Mikoshiba K: A potential approach for gene therapy targeting hepatoma using a liver-specific promoter on a retroviral vector. Cell Struct Funct 16: 503-510, 1991.

4. Kuriyama S, Nakatani T, Masui K, Sakamoto T, Tominaga K, Yoshikawa M, Fukui H, Ikenaka K and Tsujii T: Bystander effect caused by suicide gene expression indicates the feasibility of gene therapy for hepatocellular carcinoma. Hepatology 22: 1838-1846, 1995.

5. Cao G, Kuriyama S, Du P, Sakamoto T, Kong X, Masui K and Qi Z: Complete regression of established murine hepatocellular carcinoma by in vivo tumor necrosis factor a gene transfer. Gastroenterology 112: 501-510, 1997.

6. Kuriyama S, Masui K, Kikukawa M, Sakamoto T, Nakatani T, Nagao S, Yamazaki M, Yoshiji H, Tsujinoue H, Fukui H, Yoshimatsu $\mathrm{T}$ and Ikenaka K: Complete cure of established murine hepatocellular carcinoma is achievable by repeated injections of retroviruses carrying the herpes simplex virus thymidine kinase gene. Gene Ther 6: 525-533, 1999. 
7. Nakatani T, Kuriyama S, Tominaga K, Tsujimoto T, Mitoro A, Yamazaki M, Tsujinoue H, Yoshiji H, Nagao S and Fukui H: Assessment of efficiency and safety of adenovirus mediated gene transfer into normal and damaged murine livers. Gut 47: 563-570, 2000 .

8. Nagao S, Kuriyama S, Okuda H, Tominaga K, Nakatani T, Tsujinoue H, Yoshiji $\mathrm{H}$ and Fukui $\mathrm{H}$ : Adenovirus-mediated gene transfer into tumors: evaluation of direct readministration of an adenoviral vector into subcutaneous tumors of immunocompetent mice. Int J Oncol 18: 57-65, 2001.

9. Tsujinoue H, Kuriyama S, Nakatani T, Yoshiji H, Akahane T, Toyokawa Y, Fukui H, Yoshimatsu T and Ikenaka K: Amelioration of retrovirus-mediated gene transfer into hepatocellular carcinoma cells. Int J Oncol 18: 801-807, 2001.

10. Kuriyama S, Mitoro A, Tsujinoue H, Nakatani T, Yoshiji H, Tsujimoto T, Yamazaki M and Fukui H: Particle-mediated gene transfer into murine livers using a newly developed gene gun. Gene Ther 7: 1132-1136, 2000.

11. Kuriyama S, Yoshiji H, Nakai S, Deguchi A, Uchida N, Kimura Y, Inoue $\mathrm{H}$, Kinekawa $\mathrm{F}$, Ogawa M, Nonomura T, Masaki T, Kurokohchi K and Watanabe S: Adenovirus-mediated gene transfer into rat livers: comparative study of retrograde intrabiliary and antegrade intraportal administration. Oncol Rep 13: 69-74, 2005.

12. Kuriyama S, Yoshiji H, Deguchi A, Nakai S, Ogawa M, Nonomura T, Kimura Y, Inoue $\mathrm{H}$, Kinekawa F, Tsujimoto $\mathrm{T}$, Masaki T, Kurokohchi K and Uchida N: Safe and efficient trangene expression in rat hepatocytes induced by adenoviral administration into the biliary tract. Oncol Rep 13: 825-830, 2005.

13. Kuriyama S, Yoshiji H, Tominaga K, Tsujinoue H, Nakatani T, Tsujimoto T, Okuda H, Akahane T, Deguchi A, Nakai S, Masaki T and Uchida N: Repetitive and safe transgene expression in rat liver is achievable by adnoviral infusion into the common bile duct. Int J Mol Med 16: 503-508, 2005.

14. Allgaier HP, Deibert P, Zuber I, Olschewski M and Blum HE: Percutaneous radiofrequency interstitial thermal ablation of small hepatocellular carcinoma. Lancet: 353, 1999.

15. Goldberg SN, Gazelle GS, Solbiati L, Livraghi T, Tanabe KK, Hahn PF and Mueller PR: Ablation of liver tumors using percutaneous RF therapy. Am J Roentgenol 170: 1023-1028, 1998.

16. Curley SA, Izzo F, Ellis LM and Vauthey NJ: Radiofrequency ablation of hepatocellular cancer in 110 patients with cirrhosis. Ann Surg 232: 381-391, 2000.

17. Kuriyama S: Improved survival benefits with radiofrequency ablation for liver cancer. Cancer Treat Rev 31: 408-412, 2005.

18. Solbiati L, Goldberg SN, Ierace T, Livraghi T, Meloni F, Dellanoce M, Sironi S and Gazelle GS: Hepatic metastases: percutaneous radio-frequency ablation with cooled-tip electrodes. Radiology 205: 367-372, 1997.

19. Solbiati L, Lerace T, Goldberg SN, Sironi S, Livraghi T, Fiocca R, Servadio G, Rizzatto G, Mueller PR, Del Maschio A and Gazelle GS: Percutaneous US-guided radio-frequency tissue ablation of liver metastases: treatment and follow-up in 16 patients. Radiology 202: 195-203, 1997.

20. Kurokohchi K, Watanabe S, Masaki T, Hosomi N, Funaki T, Arima K, Yoshida S, Miyauchi Y and Kuriyama S: Combined use of percutaneous ethanol injection and radiofrequency ablation for the effective treatment of hepatocellular carcinoma. Int J Oncol 21: 841-846, 2002.

21. Kurokohchi K, Watanabe S, Masaki T, Hosomi N, Funaki T, Arima K, Yoshida S, Nakai S, Murota M, Miyauchi Y and Kuriyama S: Combination therapy of percutaneous ethanol injection and radiofrequency ablation against hepatocellular carcinomas difficult to treat. Int J Oncol 21: 611-615, 2002.
22. Kurokohchi K, Masaki T, Miyauchi Y, Hosomi N, Yoneyama H, Yoshida S, Himoto T, Deguchi A, Nakai S, Inoue H, Watanabe S and Kuriyama S: Efficacy of combination therapies of percutaneous or laparoscopic ethanol-lipiodol injection and radiofrequency ablation. Int J Oncol 25: 1737-1743, 2004.

23. Kurokohchi K, Masaki T, Himoto T, Deguchi A, Nakai S, Yoneyama H, Yoshida S, Kimura Y, Inoue H, Kinekawa F, Kimura Y, Yoshitake A, Izuishi K, Watanabe S and Kuriyama S: Successful laparoscopic radiofrequency ablation of hepatocellular carcinoma adhered to the mesentery after transcatheter arterial embolization. Oncol Rep 13: 65-68, 2005.

24. Kurokohchi K, Watanabe S, Masaki T, Hosomi N, Miyauchi Y, Himoto T, Kimura Y, Nakai S, Deguchi A, Yoneyama H, Yoshida $\mathrm{S}$ and Kuriyama S: Comparison between combination therapy of percutaneous ethanol injection and radiofrequency ablation and radiofrequency ablation alone for patients with hepatocellular carcinoma. World J Gastroenterol 11: 1426-1432, 2005.

25. Kurokohchi K, Masaki T, Watanabe S, Nakai S, Deguchi A, Morishita A, Yoneyama H, Ohgi T, Ono M, Yoshitake A, Kako T, Ohmachi N, Kiuchi T, Maeta T, Yoshida M, Mori Y, Kohi $\mathrm{F}$ and Kuriyama S: Time-lag performance of radiofrequency ablation after percutaneous ethanol injection for the treatment of hepatocellular carcinoma. Int J Oncol 28: 971-976, 2006.

26. Kitamoto M, Imagawa M, Yamada H, Watanabe C, Sumioka M, Satoh O, Shimamoto M, Kodama M, Kimura S, Kishimoto K, Okamoto Y, Fukuda Y and Dohi K: Radiofrequency ablation in the treatment of small hepatocellular carcinomas: comparison of the radiofrequency effect with and without chemoembolization. Am J Roentgenol 181: 997-1003, 2003.

27. Koda M, Murawaki Y, Mitsuda A, Oyama K, Okamoto K, Idobe Y, Suou T and Kawasaki H: Combination therapy with transcatheter arterial chemoembolization and percutaneous ethanol injection compared with percutaneous ethanol injection alone for patients with small hepatocellular carcinoma. Cancer 92: 1516-1524, 2001

28. Yamasaki T, Kurokawa F, Shirahashi H, Kusano N, Hironaka K and Okita K: Percutaneous radiofrequency ablation therapy with combined angiography and computed tomography assistance for patients with hepatocellular carcinoma. Cancer 91: 1342-1348, 2001.

29. Yasuda S, Ito H, Yoshikawa M, Shinozaki M, Goto N, Fujimoto H, Nasu K, Uno T, Itami J, Isobe K, Shigematsu N, Ebara M and Saisho H: Radiotherapy for large hepatocellular carcinoma combined with transcatheter arterial embolization and percutaneous ethanol injection therapy. Int J Oncol 15: 467-473, 1999.

30. Okano H, Shiraki K, Inoue H, Ito T, Yamanaka T, Deguchi M, Sugimoto K, Sakai T, Ohmori S, Murata K, Takase K and Nakano T: Combining trascatheter arterial chemoembolization with percutaneous ethanol injection therapy for small size hepatocellular carcinoma. Int J Oncol 19: 909-912, 2001.

31. Livraghi T, Goldberg SN, Monti F, Bizzini A, Lazzaroni S, Meloni F, Pellicano S, Solbiati L and Gazelle GS: Saline-enhanced radio-frequency tissue ablation in the treatment of liver metastases. Radiology 202: 205-210, 1997.

32. Hansler J, Frieser M, Schaber S, Kutschall C, Bernatik T, Muller W, Becker D, Hahn EG and Strobel D: Radiofrequency ablation of hepatocellualar carcinoma with a saline solution perfusion device: a pilot study. J Vasc Interv Radiol 14: 575-580, 2003.

33. Watanabe S, Kurokohchi K, Masaki T, Miyauchi Y, Funaki T, Inoue $\mathrm{H}$, Himoto $\mathrm{T}$, Kita $\mathrm{Y}$, Uchida $\mathrm{N}$, Touge $\mathrm{T}$, Tatsukawa $\mathrm{T}$ and Kuriyama S: Enlargement of thermal ablation zone by the combination of ethanol injection and radiofrequency ablation in excised bovine liver. Int J Oncol 24: 279-284, 2004. 